The Open Dentistry Journal
CrossMark
Content list available at: www.benthamopen.com/TODENTJ/
DOI: $10.2174 / 1874210601610010322$

RESEARCH ARTICLE

\title{
Accuracy of Panoramic Radiograph in Assessment of the Relationship Between Mandibular Canal and Impacted Third Molars
}

\author{
Weeraya Tantanapornkul", Darika Mavin, Jaruthai Prapaiphittayakun, Natnicha Phipatboonyarat \\ and Wanchanok Julphantong
}

Department of Oral Diagnosis, Faculty of Dentistry, Naresuan University, Phitsanulok 65000, Thailand

Received: February 1, 2016

Revised: April 10, 2016

Accepted: May 9, 2016

\section{Abstract:}

Background:

The relationship between impacted mandibular third molar and mandibular canal is important for removal of this tooth. Panoramic radiography is one of the commonly used diagnostic tools for evaluating the relationship of these two structures.

\section{Objectives:}

To evaluate the accuracy of panoramic radiographic findings in predicting direct contact between mandibular canal and impacted third molars on 3D digital images, and to define panoramic criterion in predicting direct contact between the two structures.

\section{Methods:}

Two observers examined panoramic radiographs of 178 patients (256 impacted mandibular third molars). Panoramic findings of interruption of mandibular canal wall, isolated or with darkening of third molar root, diversion of mandibular canal and narrowing of third molar root were evaluated for 3D digital radiography. Direct contact between mandibular canal and impacted third molars on 3D digital images was then correlated with panoramic findings. Panoramic criterion was also defined in predicting direct contact between the two structures.

\section{Results:}

Panoramic findings of interruption of mandibular canal wall, isolated or with darkening of third molar root were statistically significantly correlated with direct contact between mandibular canal and impacted third molars on 3D digital images $(p<0.005)$, and were defined as panoramic criteria in predicting direct contact between the two structures.

\section{Conclusion:}

Interruption of mandibular canal wall, isolated or with darkening of third molar root observed on panoramic radiographs were effective in predicting direct contact between mandibular canal and impacted third molars on 3D digital images. Panoramic radiography is one of the efficient diagnostic tools for pre-operative assessment of impacted mandibular third molars.

Keywords: 3D digital radiograph, Inferior alveolar nerve, Panoramic radiograph, Third molar.

\section{INTRODUCTION}

Removal of impacted mandibular third molar is one of the routine operations in oral and maxillofacial surgery [1]. Most of the common postoperative complications are mild and reversible, although inferior alveolar nerve damage is

\footnotetext{
* Address correspondence to this author at the Department of Oral Diagnosis, Faculty of Dentistry, Naresuan University, Phitsanulok 65000, Thailand; E-mail: weerayatan@yahoo.com
} 
one of the most serious consequences. Postoperative complications such as swelling, trismus and pain are not difficult to manage, but the functional loss of sensory innervations of the lower lip may cause traumatic injuries and fibromas, scar tissue, and mucocele formation on the mucosa [2].

The frequency of inferior alveolar nerve paraesthesia ranges between $0.4 \%$ and $8.4 \%$ [3], whereas permanent risk is usually less than $1 \%$ [4]. Although the incidences of these complications are low, they can be serious. Panoramic radiographs are imaging modality most commonly used by oral and maxillofacial surgeons to view impacted third molars and to estimate the risk of inferior alveolar nerve injuries [5 - 9]. It is known that the risk of inferior alveolar nerve paraesthesia dramatically increases when there is direct contact between the nerve and third molar root [10, 11]. Thus, it is important to evaluate the topographic relationship between the mandibular canal and impacted third molar preoperatively. There were reports $[6,7,9,11]$ that showed the following 4 panoramic features were significantly associated with inferior alveolar nerve exposure following third molar extraction: interruption of mandibular canal, darkening of third molar root, diversion of mandibular canal and narrowing of third molar root. In addition, many studies reported that the interruption of mandibular canal was the most found panoramic feature that associated with direct contact between the two structures, which could be the risk of nerve injury and paraesthesia $[2,6,8,12]$.

When the panoramic radiograph is suggestive of an intimate relationship between the impacted tooth and the mandibular canal, medical CT or cone-beam CT is recommended for further investigation to demonstrate the threedimensional relationship between the two structures $[12,13]$. However, one obvious drawback of medical CT is the much higher radiation dose that the patient receives compared with panoramic radiography [13]. Although cone-beam CT provides adequate image quality associated with a lower exposure dose, the high cost of examination in view of the socioeconomic conditions of some developing countries makes the use of panoramic radiography clearly justified in the preoperative evaluation in third molar surgery.

Several studies have demonstrated that the presence of two or more signs on a panoramic radiograph indicates an increased risk of inferior alveolar nerve exposure or injury [2, 4, 14, 15]. However, there are few studies reporting panoramic radiographic findings, separately or association, in predicting direct contact between mandibular canal and impacted third molars. To the best of our knowledge, there was only a study by Neves et al. [6] which was performed to assess the reliability of four panoramic findings, both individually and in association, in predicting the absence of corticalization between the mandibular canal and the third molar on cone-beam CT images. They concluded that darkening of roots and interruption of white line observed on panoramic radiographs, both as isolated findings and in association, were effective in determining the risk relationship between the tooth roots and the mandibular canal, requiring three-dimensional evaluation of the case.

It is still uncertain whether panoramic findings suggesting the interruption of the mandibular canal in association with the other 2 panoramic findings; diversion of mandibular canal and narrowing of third molar root are effective in predicting direct contact between mandibular canal and impacted third molar. To clarify this clinical question, this study was performed to evaluate the accuracy of panoramic radiographic findings of interruption of mandibular canal, separately or in association with darkening of third molar root, diversion of mandibular canal and narrowing of third molar root, in predicting direct contact between mandibular canal and impacted third molars on 3D digital images, and to define panoramic criterion in predicting direct contact between the two structures.

\section{METHODS}

The present study was performed following approval of the institutional ethical committee, and informed consent was obtained from all the volunteers.

\section{Patients and Data Collection}

All patients who were examined in Oral Diagnosis and Oral Medicine clinic, Dental Hospital, Naresuan University, for extraction of impacted mandibular third molar between March 2014 and February 2015 underwent preoperative panoramic radiography. Among them, 178 patients (256 impacted teeth), of which 60 were males and 118 were females (mean age 21.03 years; range, 16-54 years), who underwent additional examination by three-dimensional digital radiograph because of 4 panoramic findings; interruption of mandibular canal wall, darkening of third molar root, diversion of mandibular canal and narrowing of third molar root were included in this study (Fig. 1). 


\section{Imaging}

Digital panoramic radiograph were taken using Kodak 9000C 3D (Carestream Health, Inc., Rochester, NY) operated at 60-70 kVp and 8-10 mA, with CCD (charge-coupled device) optical fiber sensor. The panoramic images were evaluated on LCD monitor (Dell Optiplex 990, Dell Inc., Penang, Malaysia).

For the 3-dimensional digital radiograph, the same x-ray machine was used. The impacted mandibular third molars were imaged at $70 \mathrm{kVp}$, tube current of $8 \mathrm{~mA}$ with the exposure time of 10 seconds. After scanning, contiguous sectional images in 3 directions, that is, parallel, cross and horizontal section images were reconstructed from the projection data with a slice width of $1 \mathrm{~mm}$. Scrolling the contiguous sectional images using dedicated software (Carestream Health, Inc., Rochester, NY), the observers evaluated the images in each section on a LCD monitor by scrolling the contiguous sectional images. A specific software was used.

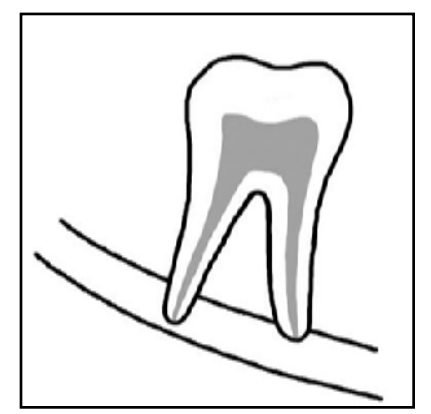

A

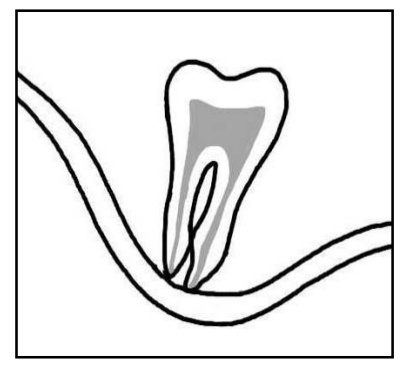

C

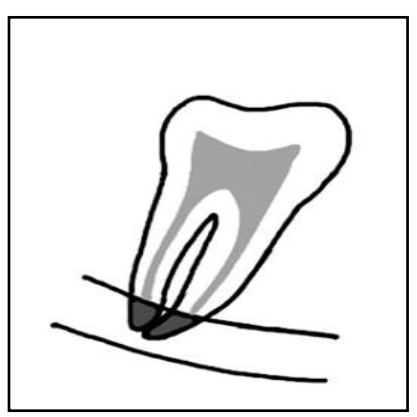

B

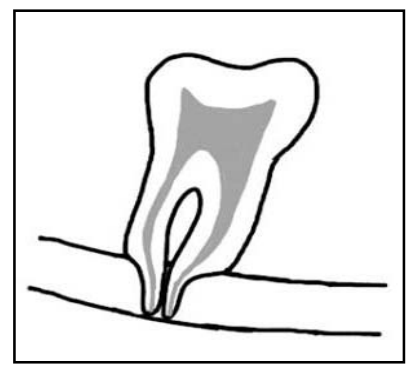

Fig. (1). Schematic drawings of the 4 panoramic features evaluated in the present study. A, Interruption of mandibular canal wall. B, Darkening of third molar root. C, Diversion of mandibular canal. D, Narrowing of third molar root.

\section{Evaluation of Images}

Two observers (one oral radiologist and one general dentist) evaluated the panoramic and 3D digital images independently for the relationship between the impacted mandibular third molar and mandibular canal. Two hundred and fifty-six third molars were divided into 2 groups. In each group, panoramic images were first evaluated, and after 2 weeks, 3D digital images were evaluated. 3D digital images were presented to the observers in randomised order so that they could not refer to the panoramic features. When disagreement existed between the assessments of the 2 observers, consensus was reached by discussion. Inter-observer agreement was evaluated using kappa statistics.

For the evaluation of 3D digital images, the presence or absence of direct contact between the third molar root and mandibular canal was three-dimensionally evaluated. It was considered that direct contact was present when loss of bone tissue between the 2 structures was observed on all 3 sections.

The optimal panoramic criterion in predicting direct contact between the two structures was also determined.

\section{Statistical Analysis}

Data were analysed using Statistical Package for the Social Science for Windows (SPSS 17.0 North western University Information Technology, Evanston, IL). The kappa values were calculated to assess inter-observer agreement. A kappa value of less than 0.40 was considered to show poor agreement; that of $0.40-0.59$, fair agreement; 
that of 0.60-0.74, good agreement; and that of 0.75-1.00, excellent agreement [16]. Comparison between panoramic and $3 \mathrm{D}$ digital image findings was performed using Fisher's exact test, with a significant level of $p<0.05$.

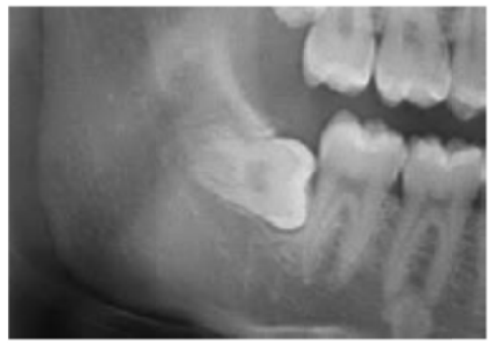

A

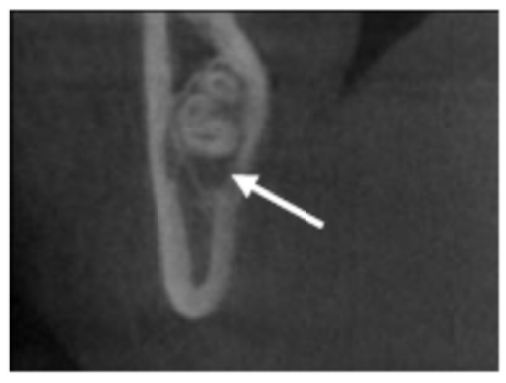

C

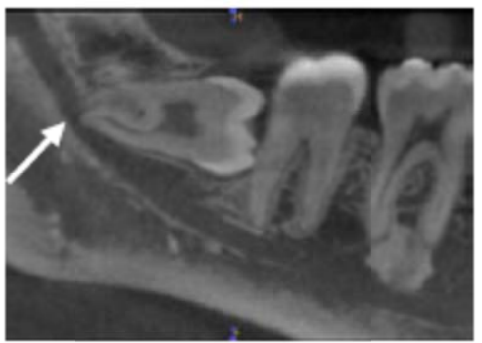

B

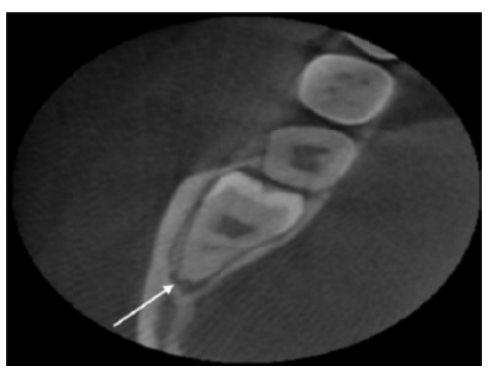

Fig. (2). A, Panoramic radiographic finding of interruption of mandibular canal wall by third molar root. B, C, and D, 3-dimensional digital images (sagittal, coronal, and axial planes) of the same tooth indicated direct contact between the two structures (arrows).

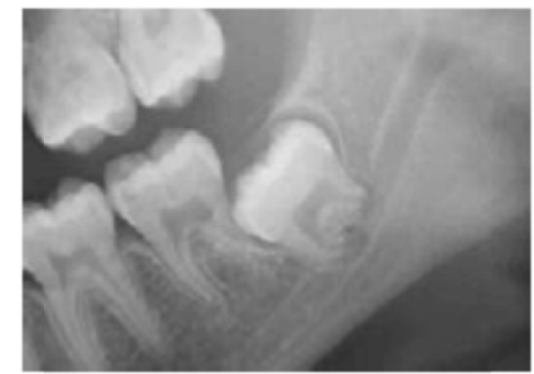

A

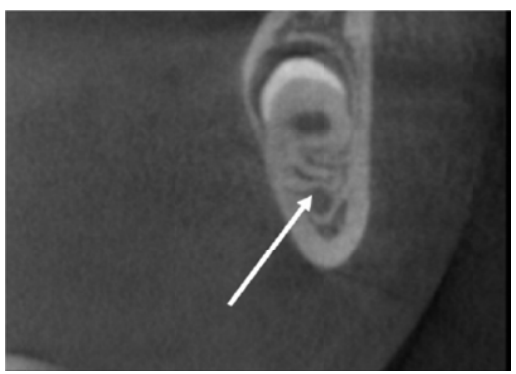

C

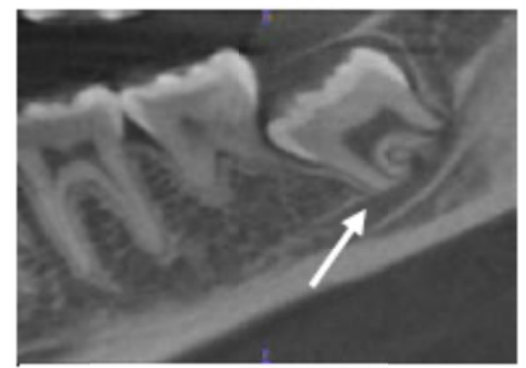

B

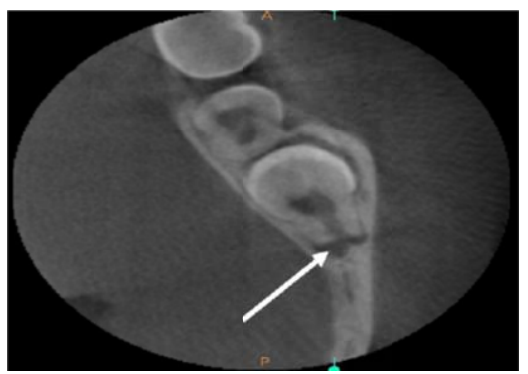

D

Fig. (3). A, Panoramic radiographic finding of interruption of mandibular canal wall by third molar root association with darkening of the root. B, C, and D, 3-dimensional digital images (sagittal, coronal, and axial planes) of the same tooth indicated direct contact between the two structures (arrows).

\section{RESULTS}

Two representative cases are shown in Fig. (2) and (3). Fig. (2) showed the panoramic radiographic finding of 
interruption of mandibular canal wall by third molar root, which indicated direct contact between the two structures on 3-dimensional digital images (sagittal, coronal, and axial planes). Fig. (3), panoramic radiographic finding of interruption of mandibular canal wall by third molar root association with darkening of the root was also indicated direct contact between the two structures on 3-dimensional digital images. Table 1 summarizes the frequencies of panoramic radiographic findings. Among 256 impacted teeth, the finding of interruption of mandibular canal wall was the most frequent finding (177 teeth, 69.14\%), the association between 3 findings (interruption of mandibular canal wall, association with darkening of third molar root, and narrowing of third molar root) and 4 findings were least found (1 tooth for each, 0.39\%).

Table 1. The frequencies of panoramic radiographic findings.

\begin{tabular}{|l|c|c|}
\hline \multicolumn{1}{|c|}{ Panoramic findings } & No. of teeth & \% \\
\hline INT & 177 & 69.14 \\
\hline INT + DAR & 56 & 21.88 \\
\hline INT + DI & 13 & 5.08 \\
\hline INT + NA & 4 & 1.56 \\
\hline INT + DAR + DI & 4 & 1.56 \\
\hline INT + DAR + NA & 1 & 0.39 \\
\hline INT + DAR + DI + NA & 1 & 0.39 \\
\hline \multicolumn{2}{|c|}{256} & 100 \\
\hline
\end{tabular}

(INT, interruption of mandibular canal; DAR, darkening of third molar root; DI, diversion of mandibular canal; NA, narrowing of third molar root).

The accuracy of panoramic radiographic findings in predicting direct contact between mandibular canal and impacted third molars on 3D digital images was shown in Table 2. Only interruption of mandibular canal wall either isolated or in association with darkening of third molar root, indicated a statistically significant association with the direct contact between the two structures on 3D digital images ( $p<0.005$ for each) and were defined as panoramic criteria. Inter-observer agreement was excellent for the assessment of panoramic and 3D digital images, with kappa values of 0.76 and 0.78 , respectively.

Table 2. Correlation between panoramic and 3D digital radiographic findings.

\begin{tabular}{|l|c|c|c|}
\hline \multicolumn{1}{|c|}{ Panoramic findings } & No. of teeth & $\begin{array}{c}\text { Direct contact in 3D } \\
\text { images }\end{array}$ & $\boldsymbol{p}$ value \\
\hline INT & 177 & 136 & $<0.005$ \\
\hline INT + DAR & 56 & 55 & $<0.005$ \\
\hline INT + DI & 13 & 13 & 0.091 \\
\hline INT + NA & 4 & 4 & 0.486 \\
\hline INT + DAR + DI & 4 & 4 & 0.486 \\
\hline INT + DAR + NA & 1 & 1 & 0.836 \\
\hline INT + DAR + DI + NA & 1 & 1 & 0.836 \\
\hline
\end{tabular}

(INT, interruption of mandibular canal; DAR, darkening of third molar root; DI, diversion of mandibular canal; NA, narrowing of third molar root).

\section{DISCUSSION}

The accurate preoperative prediction of direct contact between inferior alveolar nerve and impacted third molar is very useful for warning patients of the potential risk of postoperative dysesthesia and obtaining informed consent. Radiological assessment is essential in evaluating the relationship between these 2 structures, and panoramic images are most commonly used for this purpose.

Although panoramic images cannot provide three-dimensional information, numerous clinical studies [2, 5, 7, 11-13, 17] have been performed to determine panoramic findings suggestive of inferior alveolar nerve exposure or postoperative dysesthesia. In addition, many studies reported the panoramic findings that associated direct contact between inferior alveolar nerve and impacted third molar on computed tomography or cone-beam CT images [8, 14, 18]. In the present study, the most frequent panoramic radiographic finding was interruption of mandibular canal (69.14\%), in conformity with previously published studies $[2-4,6,12]$.

The anatomical proximity of the roots of third molar and the mandibular canal can result in nerve injuries during extraction of third molars [6]. To avoid this complication, several studies have proposed risk factors based on the 
panoramic findings $[2,3,13,14]$. However, as a two-dimensional examination, it does not provide specific diagnostic information about the relationship between third molar and mandibular canal. Knowledge of this relationship information allows for secure management in cases of severe impactions [6].

Several studies have demonstrated that the presence of two or more signs on a panoramic radiograph indicates and increased risk of inferior alveolar nerve exposure or injury [2, 4, 14, 15]. However, there are few studies reporting panoramic radiographic findings, separately or association, in predicting direct contact between mandibular canal and impacted third molars. separately or association, in predicting direct contact between mandibular canal and impacted third molars. To our knowledge, there was only a study by Neves et al. [6] which was performed to assess the reliability of four panoramic findings, both individually and in association, in predicting the absence of corticalization between the mandibular canal and the third molar on cone-beam CT images. They concluded that darkening of roots and interruption of white line observed on panoramic radiographs, both as isolated findings and in association, were effective in determining the risk relationship between the tooth roots and the mandibular canal, requiring threedimensional evaluation of the case. In the present study, isolated finding of interruption of mandibular canal wall, and in association with darkening of third molar root, were accurate and effective in predicting direct contact between inferior alveolar nerve and impacted third molar on 3D digital images. These two features were then defined as panoramic criteria. Although our study results seem different from Neves et al. [6], both studies had the same effective and accurate panoramic findings in predicting direct contact between the two structures. Clinical studies have demonstrated that the absence of corticalization between the tooth roots and the mandibular canal on spiral CT images [20] and inferior alveolar nerve exposure [20,21] are significantly associated only with some panoramic radiographic signs, in particular, darkening of roots and interruption of mandibular canal. Szalma et al. [21] identified three signs on panoramic radiograph that were significantly associated with inferior alveolar nerve paraesthesia (interruption of white line, diversion of the mandibular canal and darkening of roots). On the other hand, Hasegawa et al. [5] concluded that panoramic radiography alone does not provide sufficiently reliable images required for predicting nerve lesions. As a result, when the panoramic image is suggestive of an intimate relationship between the impacted tooth and the mandibular canal, CT is recommended for further investigation.

It has been observed that only 3D examinations, i.e. $\mathrm{CT}$, cone-beam $\mathrm{CT}$, and MRI are effective in determining the true relationship of the tooth roots and the mandibular canal $[12,14,19,20,22,23]$. In the view of socioeconomic conditions of some developing countries including Thailand, the high cost of those examinations (also 3D digital radiograph used in the present study) and the radiation dose (for CT) makes the use of panoramic radiography clearly justified in the preoperative evaluation of third molar removal.

In the present study, we found that 20 out of 62 teeth $(32.26 \%)$ with darkening of third molar root could be associated with thinning or perforation of the lingual cortex by the tooth roots observed on 3D images. This observation was also found in previous studies [9, 22].

\section{CONCLUSION}

Panoramic radiographic findings of interruption of mandibular canal wall, both isolated and in association with darkening of third molar root, were accurate and effective in predicting direct contact between inferior alveolar nerve and impacted third molar on 3D digital images. These two features were also defined as panoramic criteria. This study confirmed that panoramic radiography is an effective method for preoperative assessment of impacted mandibular third molars.

\section{CONFLICT OF INTEREST}

The authors confirm that this article content has no conflict of interest.

\section{ACKNOWLEDGEMENTS}

WT conceptualized and designed the study. WT, DM, JP, NP, and WJ carried out the study, data collection, performed the statistical analysis, read and approved the final manuscript.

\section{REFERENCES}

[1] Bataineh AB. Sensory nerve impairment following mandibular third molar surgery. J Oral Maxillofac Surg 2001; 59(9): $1012-7$. [http://dx.doi.org/10.1053/joms.2001.25827] [PMID: 11526568]

[2] Szalma J, Lempel E, Jeges S, Szabó G, Olasz L. The prognostic value of panoramic radiography of inferior alveolar nerve damage after 
mandibular third molar removal: retrospective study of 400 cases. Oral Surg Oral Med Oral Pathol Oral Radiol Endod 2010; $109(2)$ : $294-302$. [http://dx.doi.org/10.1016/j.tripleo.2009.09.023] [PMID: 19846324]

[3] Jerjes W, Swinson B, Moles DR, et al. Permanent sensory nerve impairment following third molar surgery: a prospective study. Oral Surg Oral Med Oral Pathol Oral Radiol Endod 2006; 102(4): e1-7. [http://dx.doi.org/10.1016/j.tripleo.2006.01.016] [PMID: 16997083]

[4] Gomes AC, Vasconcelos BC, Silva ED, Caldas AdeF Jr, Pita NIC. Sensitivity and specificity of pantomography to predict inferior alveolar nerve damage during extraction of impacted lower third molars. J Oral Maxillofac Surg 2008; 66(2): 256-9. [http://dx.doi.org/10.1016/j.joms.2007.08.020] [PMID: 18201605]

[5] Hasegawa T, Ri S, Shigeta T, et al. Risk factors associated with inferior alveolar nerve injury after extraction of the mandibular third molar--a comparative study of preoperative images by panoramic radiography and computed tomography. Int J Oral Maxillofac Surg 2013; 42(7): 843-51. [http://dx.doi.org/10.1016/j.ijom.2013.01.023] [PMID: 23499150]

[6] Neves FS, Souza TC, Almeida SM, Haiter-Neto F, Freitas DQ, Bóscolo FN. Correlation of panoramic radiography and cone beam CT findings in the assessment of the relationship between impacted mandibular third molars and the mandibular canal. Dentomaxillofac Radiol 2012; 41(7): 553-7. [http://dx.doi.org/10.1259/dmfr/22263461] [PMID: 22282507]

[7] Palma-Carrió C, García-Mira B, Larrazabal-Morón C, Peñarrocha-Diago M. Radiographic signs associated with inferior alveolar nerve damage following lower third molar extraction. Med Oral Patol Oral Cir Bucal 2010; 15(6): e886-90. [http://dx.doi.org/10.4317/medoral.15.e886] [PMID: 20526245]

[8] Park W, Choi JW, Kim JY, Kim BC, Kim HJ, Lee SH. Cortical integrity of the inferior alveolar canal as a predictor of paresthesia after thirdmolar extraction. J Am Dent Assoc 2010; 141(3): 271-8. [http://dx.doi.org/10.14219/jada.archive.2010.0160] [PMID: 20194382]

[9] Tantanapornkul W, Okochi K, Bhakdinaronk A, Ohbayashi N, Kurabayashi T. Correlation of darkening of impacted mandibular third molar root on digital panoramic images with cone beam computed tomography findings. Dentomaxillofac Radiol 2009; 38(1): 11-6. [http://dx.doi.org/10.1259/dmfr/83819416] [PMID: 19114418]

[10] Rood JP. Degrees of injury to the inferior alveolar nerve sustained during the removal of impacted mandibular third molars by the lingual split technique. Br J Oral Surg 1983; 21(2): 103-16.

[http://dx.doi.org/10.1016/0007-117X(83)90054-9] [PMID: 6575812]

[11] Sedaghatfar M, August MA, Dodson TB. Panoramic radiographic findings as predictors of inferior alveolar nerve exposure following third molar extraction. J Oral Maxillofac Surg 2005; 63(1): 3-7. [http://dx.doi.org/10.1016/j.joms.2004.05.217] [PMID: 15635549]

[12] Tantanapornkul W, Okouchi K, Fujiwara Y, et al. A comparative study of cone-beam computed tomography and conventional panoramic radiography in assessing the topographic relationship between the mandibular canal and impacted third molars. Oral Surg Oral Med Oral Pathol Oral Radiol Endod 2007; 103(2): 253-9. [http://dx.doi.org/10.1016/j.tripleo.2006.06.060] [PMID: 17234544]

[13] Monaco G, Montevecchi M, Bonetti GA, Gatto MR, Checchi L. Reliability of panoramic radiography in evaluating the topographic relationship between the mandibular canal and impacted third molars. J Am Dent Assoc 2004; 135(3): 312-8. [http://dx.doi.org/10.14219/jada.archive.2004.0179] [PMID: 15058618]

[14] Nakamori K, Fujiwara K, Miyazaki A, et al. Clinical assessment of the relationship between the third molar and the inferior alveolar canal using panoramic images and computed tomography. J Oral Maxillofac Surg 2008; 66(11): 2308-13.

[http://dx.doi.org/10.1016/j.joms.2008.06.042] [PMID: 18940497]

[15] Ghaeminia H, Meijer GJ, Soehardi A, Borstlap WA, Mulder J, Bergé SJ. Position of the impacted third molar in relation to the mandibular canal. Diagnostic accuracy of cone beam computed tomography compared with panoramic radiography. Int J Oral Maxillofac Surg 2009; 38(9): 964-71.

[http://dx.doi.org/10.1016/j.ijom.2009.06.007] [PMID: 19640685]

[16] Streiner DL, Norman GR. Health measurement scales. $4^{\text {th }}$ ed. Oxford: Oxford University Press 1994.

[17] Rood JP. Degrees of injury to the inferior alveolar nerve sustained during the removal of impacted mandibular third molars by the lingual split technique. Br J Oral Surg 1983; 21(2): 103-16. [http://dx.doi.org/10.1016/0007-117X(83)90054-9] [PMID: 6575812]

[18] Shahidi S, Zamiri B, Bronoosh P. Comparison of panoramic radiography with cone beam CT in predicting the relationship of the mandibular third molar roots to the alveolar canal. Imaging Sci Dent 2013; 43(2): 105-9.

[http://dx.doi.org/10.5624/isd.2013.43.2.105] [PMID: 23807934]

[19] Nakayama K, Nonoyama M, Takaki Y, et al. Assessment of the relationship between impacted mandibular third molars and inferior alveolar nerve with dental 3-dimensional computed tomography. J Oral Maxillofac Surg 2009; 67(12): 2587-91. [http://dx.doi.org/10.1016/j.joms.2009.07.017] [PMID: 19925976]

[20] Jhamb A, Dolas RS, Pandilwar PK, Mohanty S. Comparative efficacy of spiral computed tomography and orthopantomography in preoperative detection of relation of inferior alveolar neurovascular bundle to the impacted mandibular third molar. J Oral Maxillofac Surg 2009; 67(1): 58-66. 
[http://dx.doi.org/10.1016/j.joms.2008.06.014] [PMID: 19070749]

[21] Szalma J, Lempel E, Jeges S, Olasz L. Darkening of third molar roots: panoramic radiographic associations with inferior alveolar nerve exposure. J Oral Maxillofac Surg 2011; 69(6): 1544-9.

[http://dx.doi.org/10.1016/j.joms.2010.09.009] [PMID: 21292368]

[22] Mahasantipiya PM, Savage NW, Monsour PA, Wilson RJ. Narrowing of the inferior dental canal in relation to the lower third molars. Dentomaxillofac Radiol 2005; 34(3): 154-63.

[http://dx.doi.org/10.1259/dmfr/31872903] [PMID: 15897286]

[23] Ferretti F, Malventi M, Malasoma R. Dental magnetic resonance imaging: study of impacted mandibular third molars. Dentomaxillofac Radiol 2009; 38(6): 387-92.

[http://dx.doi.org/10.1259/dmfr/29929241] [PMID: 19700532]

(C) Tantanapornkul et al.; Licensee Bentham Open.

This is an open access article licensed under the terms of the Creative Commons Attribution-Non-Commercial 4.0 International Public License (CC BY-NC 4.0) (https://creativecommons.org/licenses/by-nc/4.0/legalcode), which permits unrestricted, non-commercial use, distribution and reproduction in any medium, provided the work is properly cited. 